\title{
Cannibalism as a Metaphor of Consumerism in David Mitchell's Cloud Atlas
}

\author{
DANIELla KrisZtán \\ krisztandaniella@gmail.com
}

\begin{abstract}
This paper explores the representation of cannibalism in David Mitchell's novel, Cloud Atlas, and delineates two levels on which it appears; the first context portrays cannibalistic tribes, while the second one displays an industry of producing and recycling human clones as fast food. In addition, this analysis focuses on the confrontation of what it means to be civilized or savage, and on the emerging social issues revolving around consumer culture, as the juxtaposition of consumer society and the figure of the cannibal challenges the concept of consumer society by questioning if it is civilised at all or not.
\end{abstract}

Keywords: cannibal, consumer society, consumer culture, materialism, environmental degradation

\section{Introduction}

The theme of cannibalism often occurs in literary works, mostly with the intention to represent the notion of "otherness," with which the readers are unable to identify themselves, or have difficulties doing so. The repugnance that is triggered by the figure of the cannibal makes the motif a powerful tool to achieve an alienating effect. In David Mitchell's Cloud Atlas, the metaphor of cannibalism can be seen as interweaving with the consumer culture and society, since the phases of purchasing, consuming, and producing waste eventually lead to the maximal depletion of resources, and as such a society can destroy its future, which can be considered as an act of gradual self-consumption.

Mitchell's novel incorporates six storylines embedded into each other in a story-within-a-story manner, evoking the Russian Doll motif that, in fact, symbolizes the structure of the novel. This complex narrative structure, on the one hand, enables the reader to observe consumer society from a variety of perspectives; on the other hand, reflects on the theme of cannibalism through the way each chapter is eaten up by the preceding one. Furthermore, the novel displays cannibalism on two different levels: the tribal one, which portrays cannibalistic tribes, and the industrial one, referring to the industry of producing then recycling human clones as fast food. My paper focuses on the representation of cannibalism in Cloud At- 
las, the tension between being civilized or savage, and the emerging social issues revolving around consumerism-the shifting personal and social values due to the increasing influence of materialism, as well as the nonchalance and ignorance about the exploitation of natural resources.

\section{Narrative Technique and the Russian Doll Structure}

Cloud Atlas demonstrates a unique technique of narration employing multiple storylines. It introduces six stories that all exemplify different genres, and as a further twist, each of them are linked together by being interrupted by the succeeding story. The first five narratives each stop abruptly in the middle, until the sixth unfolds without interruption, and then, in a reversed order mirroring the first half of the novel, all the chapters come to their conclusion. The first narrative titled "The Pacific Journal of Adam Ewing" is written in the manner of a journal or travel narrative, which is read by the protagonist of the second story-Robert Frobisher who himself is the composer of the seventeen letters constituting the "Letters from Zedelghem." Subsequently, these get in Luisa Rey's possession, who is the heroine of the detective thriller titled "Half-Lives: The First Luisa Rey Mystery." The following chapter- "The Ghastly Ordeals of Timothy Cavendish-"is a comic memoir that reaches the next story as a film adaptation. Thus, in "An Orison of Sonmi-451," Sonmi, the human clone condemned to death, draws strength and comfort from watching this movie, while her story is transmitted through an interview that is in fact her last testimony documented by an Archivist. The last narrative is titled "Sloosha's Crossin' an' Ev'rythin' After," and according to Nazalee Raja's interview with David Mitchell, it is a vernacular story of a post-apocalyptic tribe member told around a feast. The narrator Zachry recollects a determining period of his life, in which Sonmi's testimony plays a huge role, as, in the course of time, Sonmi became remembered as a goddess.

The settings of the episodes vary from one story to another-from the Chatham Island on the Pacific Ocean through Belgium to the United States-, whereas the temporal structure maintains a linearity. The first narrative is set around 1850 and the following chapters depict later periods. Some of them are explicitly defined, for instance, in "Letters from Zedelghem" Robert Frobisher dates his letters to 1931, while in "The First Luisa Rey Mystery" it is frequently mentioned that the episode is set in 1975. Notwithstanding, the last two stories are more difficult to anchor; even if the sub-narratives imply that the scenes take place on the Korean Peninsula and Hawaii, the exact time is debatable in both cases. This absence of a definite time at this stage of the novel is essential to obscure the borderline between 
the two dystopian chapters: the totalitarian-capitalist dystopia and the post-apocalypse. This way Mitchell unquestionably positions both prospects in the future, but without any specific predictions regarding when they would occur.

The interconnectedness arching over time and space not only achieves a feeling of totality, a universal wholeness, but also gives the impression of a story-within-a-story manner of the narrative structure. In fact, if we want to be precise and faithful to the narrative itself, we may call it a matryoshka structure, seeing that this phrase appears in three of the six stories. In the "Letters from Zedelghem," the title of a composition is "Matruschka Doll Variations" (Mitchell 2014, 52), in "An Orison of Sonmi-451," a circus freak is called "Madame Matryoshka" (Mitchell 2014, 353), while in "The First Luisa Rey Mystery," Sixsmith, a scientist assisting Luisa Rey, gives an explanation of time as being "an infinite matrioshka doll of painted moments" (Mitchell 2014, 409). Based on Mitchell's revelation of the primordial factors in composing the novel, Sarah Johnston-Ellis notes that "through the creation of the Russian doll structure each story can be seen as to be "eaten" by its successor and later "regurgitated" by the same' to mirror and underline the overarching theme of the novel, which is the nature of predation in the pursuit for power" (qtd. in Mitchell 2005). As Mitchell affirms, Cloud Atlas is interwoven with the theme of how "individuals prey on individuals, corporations on employees, tribes on tribes, majorities on minorities, and how present generations 'eat' the sustenance of future generations" (Mitchell 2005). This predacity characterizes each narrative; the novel provides the "repeated mantra of its first predator, Henry Goose" (Hicks 2016, 64) that "the Weak are Meat the Strong do Eat" (Mitchell 2014, 508). Accordingly, the following chapters exemplify how the "weak are poisoned, cuckolded, blackmailed, assaulted, imprisoned, enslaved, and, ultimately, eaten ... by those with more cunning and power" (Hicks 2016, 64).

\section{Tribal Cannibalism}

Based on preliminary works investigating the metaphor of cannibalism, Bartolovich (1998) concludes that the cannibal has become "a site of conflict in which different groups meet in their quite different uses and accentuation of the term, and struggle over its meaning" (209). It is ascertained, however, that the figure of the cannibal conveys a sense of hostility. In the first place, it is constantly associated with barbarity, cruelty, and a lack of moral limits, owing to the fact that it violates the taboo of consuming one's own kind, a fellow human being, which, evidently, additionally comprises the act of murdering that is in itself another morally condemnable deed. The figure of the cannibal, for this reason, evokes an instantaneous 
repulsion, which makes it an apt tool in literature to display a sense of otherness and alienation, an unsurmountable difference.

Kristen Guest in her study in 2001 notes that "the idea of cannibalism prompts a visceral reaction among people precisely because it activates our horror of consuming others like ourselves. Ultimately, then, it is the shared humanness of cannibals and their victims that draws our attention to the problems raised by the notion of absolute difference" (3). The paradox evoked by the image of humans ingesting other humans as food questions the self-identification of the cannibal itself and the boundaries that are established to divide the "edible" and the "non-edible" human being. The shared humanness of predator and victim discussed by Guest is the origin and the centre of this dilemma.

Both chapters of the novel incorporating cannibalism in the form of primitive tribes are temporally significantly distanced from the reader. The terror and incomprehensibility of such cruelty is more credible in the historically detached and the dystopian context, due to the fact that the reader may feel secure of the assumption that in our advanced and civilized - a term that will need further explanation-society that kind of brutality and inhumanity could never occur.

"The Pacific Journal of Adam Ewing" is the first chapter of the novel, and at the same time, chronologically the earliest episode, since it reaches back to the mid-nineteenth century. The setting and even the form of the narrative, which resembles a travel narrative, adjusts to the historical context. "The Pacific Journal of Adam Ewing" does not incorporate cannibals explicitly, but cannibalism is employed as the backbone of the narrative as it is, from the first moment, constantly discussed, which achieves the sensation that the figure of the cannibal even in absence manages to build an atmosphere of lurking danger. The first scene introduces Dr. Henry Goose with the image of him digging out human teeth spat out by cannibals on the shore of an island on the Pacific Ocean. Consequently, the theme of cannibalism emerges at this preliminary stage, along with Goose apparently being positioned in proximity with the tribal cannibals, taking over the status of the predator. His intention is to take revenge on a noble woman in London by selling the teeth to the dentist who makes dentures for her; his benefit would be twofold, since he would not only be able to accuse the lady of eating with cannibals' teeth, but he would also earn good money for the teeth. However, this act and the intent focus on the teeth that is the symbol of eating and devouring "puts Western elites in close proximity to the act of cannibalism itself" (Bayer 2015, 352) and foreshadows their transformation into the "consumer" whose primary concern is satisfying its hunger, not only for food, but also for money, power, and social recognition.

The storyline indeed portrays consumerism at its very beginning. First of all, the idea behind the travel narrative is to explore and exhibit a field that is yet 
unknown, which geographically refers to the Pacific Ocean, while abstractly indicates the "discovery" of consumer culture. Further evidence for this is the period in which the chapter is set, the mid-nineteenth century which is connected to the first scholarly analyses about the influence of consumption on culture and society (McDonald and Wearing 2013,21). In addition, the narrative presents one of the vital elements of the development of a consumer capitalist system, the deliberate "training of appetite." The phrase is only understood in the colonial framework, as it means the aim of colonisers "to generate the most trade-beneficial 'appetites' in the natives" (Bartolovich 1998, 220), which was vital to create adequate conditions for trading. Given that the basis of trading is a difference in needs and desires, the induction of certain desires occasionally becomes fundamental.

This is precisely what the "Nazareth Smoking School" (Mitchell 2014, 501) demonstrates. The function of this institution is exactly what its name suggests, to teach how to smoke while combining it with a religious sermon. Its main purpose is to incite an addiction for tobacco in the Polynesian native people, as a way to provide them with motivation to work for the colonisers. This process gives the aboriginals a reason to value money, and a desire to accumulate it; they work, so that they can buy. Furthermore, employing the name Nazareth, that is Jesus's birthplace, also bears considerable significance. On the one hand, it marks the birth of a new era which, here, is undeniably the age of consumer culture, while, on the other hand, the religious connotation indicates the enormous impact this paradigm shift carries. As a matter of fact, in a recent study, Matthew McDonald and Stephen Wearing (2013) summarise Georg Simmel's observation that at the turn of the twentieth century consumer culture began to replace religion in aspects "that it cultivated tastes, provided a basis for the construction of self-identity and a sense of one's place in society, just as the practice of religion had done so successfully for many centuries prior" (24). This examination materializes in the novel; it is further proved by the absence of religious institutions in "An Orison of Sonmi-451," which depicts the culmination of consumer capitalism, and then by the sudden reappearance of the belief in a divine entity in "Sloosha's Crossin' an' Ev'rythin' After," the chapter that envisions a microcosm after the collapse of consumer capitalism.

"Sloosha’s Crossin' an' Ev'rythin' After" particularly seems to be centred around the question of who can be considered civilized and who is savage, while eliminating — or at least reducing to a minimum - the discourse of enlightenment, which may seem to be the easiest answer to explain what it means to be civilized. This narrative depicts a small post-apocalyptic community, the Valleysmen who are left as the only civilized society among savage and cannibalistic tribes. As previously mentioned, the locations of the last two narratives are not explicit; yet, it is defi- 
nitely known that they are separated by the "Fall" that is supposedly the decline of advanced civilization resulting in the depletion of natural resources and a global nuclear war, once again alluding to the Biblical Fall marking the triggering to Christian civilization.

In "Sloosha's Crossin' an' Ev'rythin' After," the only representative of scientific knowledge is Meronym, a member of a secluded community that is itself perishing due to an incurable plague, even though they are the descendants of genetically programmed humans modified precisely to be protected against the rough circumstances of an environment without advanced technology. The core of the chapter is her recount of how the civilized world has destroyed itself by ripping out the skies, boiling up the seas, poisoning the soil with atom, and upsetting human reproduction with defective genes (Mitchell 2014, 286), as the Valleysmen are challenged by the repercussions of these events and the loss of scientific knowledge. Meronym differentiates between the savage and the civilized human in the following way:

The savage sat'fies his needs now. He's hungry, he'll eat. He's angry, he'll knuckly. He's swellin', he'll shoot up a woman. His master is his will, an' if his will say-soes 'Kill' he'll kill. Like fangy animals ... . Now the Civ'lized got the same needs too, but he sees further. He'll eat half his food now, yay, but plant half so he won't go hungry 'morrow. He's angry, he'll stop 'n' think why so he won't get angry next time. He's swellin', well, he's got sisses an' daughters what need respectin' so he'll respect his bros' sisses an' daughters. His will is his slave, an' if his will say-soes, 'Don't!' he won't, nay. (Mitchell 2014, 318)

On the basis of this definition, savage people are more identical to animals as they are driven by impulses and desires, have little perception of a future except for an immediate one, and lack any moral understanding whatsoever-concerning their fellow human beings anyway. The civilized according to this narrative constitute the opposite; a person in possession of reason and above his or her desires, who controls them rather than is controlled by them, and as such adopts a sustainable lifestyle. This interpretation of savage and civilized denotes a significant confrontation between the dominance of the body and that of the mind, which is predominantly associated with modern Western philosophy.

In his overview of the correlation between capitalism, consumerism, and its approaches to the body, Michael Carolan (2005) describes "the dichotomy of mind and body" (88), according to which "the body is the physical, the animalistic, and the uncontrollable. It represents passion and irrationality. The mind, on the other hand, is reason. It represents the emancipating force that frees us from the bonds of nature and the shackles of desire" (Carolan 2005, 88-89). In addition, he points out the two archetypes of the body defined by Mikhail Bakhtin; the carnivalesque or grotesque and the classical. The carnival body represents the domination of the 
body and passion over mind and reason (Carolan 2005, 89), and, as Mark Paterson (2006) notes on the grotesque bodies in his study, it celebrates the "pleasure and excess as compared with the regulated, disciplined bodies of everyday socio-economic entrenchment" (89). The classical body signifies its inverse, when the mind and reason is in control of the body, rules it and suppresses its desires (Carolan $2005,89)$. Following this line of thought, cannibals can definitely be recognized as carnival bodies, seeing that they lack any kind of bodily control as they please their irrational hunger and misplaced desire for human meat. The extent to which they are characterized by uncontrollable voraciousness surpasses any sense of humanity or their "shared humanness" (Guest 2001, 2) with their victims.

Yet, the cannibal also seems to serve as a mirror to consumer society to underline the carnival side of consumers which is partly expected of them and partly disapproved. This is the result of the "dual imperatives in consumer capitalism" (Carolan 2005, 92), which at one point demands self-discipline and work, but otherwise encourages "to release control: to give in to the commodified world around us" (Carolan 2005, 92) and to the pleasures it offers. The word itself "consume" implies this paradox, because it connotes corporeality to a large extent, denoting the act of devouring and absorbing something (food, commodity, service, experience, etc.), yet besides the meaning of using up or destroying, the word originally also means consummating, "to bring to completion" (Paterson 2006, 8). Nevertheless, the relentless pursuit of the classical body is instilled into the advanced civilized society, in which consumers are supposed to achieve a perfect condition; a body that exudes youth, health, wealth, and, most importantly, self-discipline. In his study examining culture and society in the framework of capitalism, Daniel Bell observes the essential contradiction within Western bourgeois society as one between the principles of industrialism and modernist culture, which demonstrates the paradigm of the noted phenomenon:

The characteristic style of industrialism is based on the principles of economics and economizing: on efficiency, least cost, maximization, optimization, and functional rationality. Yet it is this very style that is in conflict with the advanced cultural trends of the Western world, for modernist culture emphasizes anti-cognitive and anti-intellectual modes which look longingly toward a return to instinctual sources of expression. The one emphasizes functional rationality, technocratic decision making, and meritocratic rewards; the other, apocalyptic moods and anti-rational modes of behavior. $(1978,84)$ 


\section{Industrial Cannibalism}

The most critical chapter of Cloud Atlas in relation to consumer culture is the fifth one, "An Orison of Sonmi-451." It portrays a dystopia set in the fictitious Nea So Copros, today's Seoul. This state incorporates the features of a capitalist industry and a totalitarian regime, which results in the comprehensive indoctrination of consumer values in every layer of the society. The economy, as is expected of a consumer capitalist state, depends on the continuous production and consumption of goods and services. The narrative places a heavy emphasis on the harsh representation of these two components by depicting a state based on the ruthless exploitation of enslaved human clones and manipulated citizens.

The novel—but particularly this storyline—severely criticizes consumer culture, perceiving it as necessarily generating false values for the most prestigious goods and services, while diminishing individuality and human relationships. The consumer society is mirrored in two ways in "An Orison of Sonmi-451;" the first one is evidently through the representation of the citizens, who themselves are labelled as consumers of Nea So Copros, and are presented as being oppressed and brainwashed, due to which they are not aware of their own subjection. In this not-so-distant future, microchips, which are implanted under the skin, are used for the identification of citizens. These chips register one's personal data; name, age, profession, and they even record the spending of the individual. Nevertheless, most ironically, these devices are called Souls. This single concept further proves the distorted perception of value in the narrative, since in this context the term, soul, attains a new connotation; a person's consumerist identity monitored by the state. Likewise, one of Nea So Copros' catechisms states, that a "Soul's Value is the Dollars Therein" (Mitchell 2014, 341), which implies that a person's worth depends on his or her financial status, but moving further it also suggests that the soul has lost its meaning as the spiritual part of a person. Thus, on the one hand, this case demonstrates the earlier noted lack of religious traditions in the advanced consumer culture where "the worship of commodities" (McDonald and Wearing $2013,24)$ occupies the dominant place in human value system. On the other hand, this transfer of meaning eliminates the recognition and importance of inner traits of human beings, and instead inseparably conjoins personal value with the material.

This process, however, provokes the estrangement between people, owing to the fact that the act of never-ending purchasing occupies the primary position in their lives and their emotional needs remain unsatisfied, which eventually leads to an inability to identify and manage one's feelings. The long-term deficiencies in a society arise when such an indifferent approach towards one's environment 
develops into a substantial human trait, and pleasing one's selfish interest at any costs becomes self-evident; just as Kasser (2002) maintains: "[w]hen materialistic values dominate our society, we move farther and farther from what makes us civilized. We treat each other in less humane ways. We allow the pursuit of money to take precedence over equality, the human spirit, and respectful treatment of each other" (91-92). Taking into consideration the previous section that delineated what can make people civilized, Kasser's judgment seems to be in concord with the conflict of mind and body. According to his description, the soul and the sense of humanity, as incorporeal constituents, signify the mind, and they are contrasted with money that denotes the material reality and the body. The storyline too puts great emphasis on the distinction of these two categories, insisting on the incapability of the consumer society to achieve a balance between them.

Another instance for this is provided with the quota system; for the reason that the capitalist state hinges on the purchasing and consumption of material goods and services, the citizens of Nea So Copros are forced to spend a certain amount of money each month. They have to fulfil a given quota in order to meet the obligations of their social positions; the higher a person stands in the social hierarchy, the more money he or she has to spend. Neglecting the quota involves severe consequences. An individual who disregards it, becomes excluded from the mainstream society and ends up in places that are especially maintained to serve as a terrifying example. The district Huamdonggil, for example, functions as "a chemical toilet where unwanted human waste disintegrates, discreetly; yet not quite invisibly" (Mitchell 2014, 332), which is a motivating force for the citizens to maintain the cycle of working and spending.

This instance, again resembles the dual imperatives noted by Carolan, but here the spending - that is the indulgence in the commodified world-is not only expected but becomes transformed into just as much of an obligation as working is in order to make a living. It is notable how people who do not serve the consumerist state or who diverge from its value system become devalued and dehumanized, because it suggests the commodification of humans, as they are classified based on their usefulness-here it signifies the usefulness of citizens to the state. McDonald and Wearing (2013) defines commodification as "the transformation of an object, service, time, ritual or even a person into a commodity, which is not by nature a commercial entity" (23). What Mitchell created is an apt portrayal of a consumer society that is born out of capitalism. Although, the quota system appears to be a farfetched idea, the defects of consumerism are already present in contemporary society, where appearance and belongings determine one's social standing, while the acknowledgment of a person is measured according to their financial competence. Henry Giroux's (2005) remark that "under neoliberalism everything either is for 
sale or is plundered for profit" (2) ultimately materializes in Cloud Atlas, seeing that in Nea So Copros, citizens may even sell their right to have children, this way derogating the most fundamental human relationship.

Furthermore, the other mirrors held up to consumer society are, in fact, the fabricants, who can easily be called commercial entities. They are manufactured and sold just as any other products. This exaggerated scheme definitely seems to echo the concept of commodification, and its theoretical forerunner, Karl Marx's idea of how labour "produces itself and the worker as a commodity" (McDonald and Wearing 2013,22). The dulling of clones is a form standardization to convince the public of their lack of individuality and character, thus their lack of human nature, so that their enslavement and utilization on the market would be justified. Sonmi explains it to her interviewer as "to enslave an individual distresses the conscience, but to enslave a clone is merely like owning the latest mass-produced six-wheeled ford" (Mitchell 2014, 191). This observation identifies individuality as the core of humanity, but if considering fabricants as doubles to consumers, then it accuses the consumer of lacking humanity, that is typically described as comprising kindness, compassion, and very importantly empathy; characteristics that are fundamental to functional relationships and are unattainable in an alienated society.

Yet another perception on the issue offers the fabricants as the most ideal labourers seeing that they are bred in "wombtanks" and are genetically programmed to endure long hours awake and any kind of climate or environment a simple human would not be able to survive, for instance mines or radioactive lands. Deprived of basic rights, clones are not acknowledged as humans, they function simply as mass-produced slaves for twelve years when they are slain and recycled as meat for restaurants and a substance, called Soap, for fabricants, which is, gruesomely, their only source of nourishment. This is the point where cannibalism enters the narrative.

After their death, fabricants are handled as nothing better than livestock, considering that their cadavers are processed as butchered animals in a slaughterhouse, described as being "manned by figures wielding scissors, swordsaws . . . blood-soaked, from head to toe. . . . [T] he devils down there snipped off collars, stripped clothes, shaved follicles, peeled skin, offcut hands and legs, sliced off meat, spooned organs" (Mitchell 2014, 359). The Archivist, conducting the interview with the protagonist Sonmi-451, voices the central paradox of the novel by refusing to accept how "such evil could take root in our civilized state" (Mitchell 2014, 360). However, it is simply the business of industry exploiting every possibility for a higher profit. After all, what could be more cost-efficient than the cycle of recycling the free workforce to feed the new one? Sonmi who is produced to serve in a Papa Song diner remarks that "fabricants cost very little to 
cultivate, and have no awkward hankerings for a better, freer life. As a fabricant [e] xpires after forty-eight hours without a highly genomed Soap . . . 'it' will not run away. ... [F] abricants are the ultimate organic machinery" (Mitchell 2014, 341). Indeed they are the most perfect machinery of industry and capitalism, after all, given that they depend on one specific sustenance that contains drugs, refraining them from gaining intellectual stimulation, they do not desire anything on their own and have no life at all except for the work they are programmed to doobviously, overtime is no trouble for them.

Based on the previous interpretations, it seems reasonable to state that, in the narrative, people symbolizing consumers are entirely passivized and portrayed as, what McDonald and Wearing (2013) describe as "unthinking automatons . . . manipulated and controlled by the corporate marketing and advertising machine" (8). This perspective rejects the idea of a free willed consumer; rather it regards them as agentless objects deprived of individuality, and manipulated and moulded into mass products, which is a central concern of consumer critics. The analogy of clone and consumer conveys this fear of the overall standardization of human beings in the name of globalisation. The soap that typically symbolizes cleanness, in this context, rather appears as another indicator to brainwashing, since the Soap sustaining clones contains drugs that hinder personality development and intellectual inquiry, and seats them in an unquestioned complacency, this way reflecting an era of passive and "docile bodies ... that have been discursively inscribed to embody the moral, political, and social conventions of a socio-political system" (Carolan 2005, 98).

To examine the chapter from another perspective, the figure of the fabricant can also be regarded as the key factor and epitome of the juxtaposition of cannibalism and consumerism. The basic problem with the metaphor of cannibalism representing capitalism or neoliberalism is the difference in their so-called appetite. Cannibals are characterized by "absolute, unlimited" (Bartolovich 1998, 213) consumption, seeing that satisfying their hunger equates with the termination of the agent that is the target of the cannibal's hunger. However, the "capital's own 'hunger' and 'thirst' for the 'living blood' of labour" (Bartolovich 1998, 213) cannot become so ultimate, owing to the fact that killing off its labour power- the worker-would obviously impede the functioning of the capitalist system. In "An Orison of Sonmi-451," the main source of labour power are fabricants, who are, in fact, consumed by the capitalist industry. In addition, by the process of recycling them, they become reinstalled into the capitalist system, constructing it just as the devoured (human) meat becomes an integral part of the cannibal body.

The "system of organized cannibalism" (Hicks 2016, 64) of Nea So Copros, is in analogy with "Sloosha's Crossin' an' Ev'rythin' After" which represents the threat of 
being consumed by cannibals. This parallel displays how the moral conscience of the cannibal tribes is at about the same degree as that of the corpocratic entrepreneurs, considering their similar indifference to the mass slaughter of humans they execute. It again sharply calls to attention that living in an enlightened and scientifically advanced era is not equivalent to being civilized. As a matter of fact, the novel gives a cross-reference between the distorted values of the dystopian future in "An Orison of Sonmi-451" and the present days that is represented by "The Ghastly Ordeals of Timothy Cavendish."

Cavendish's story truly mesmerizes Sonmi, probably for the reason that she identifies the resemblance between her imprisoned situation and that of Cavendish. After he signs the custody papers that he considers to be a hotel registry, he is incarcerated in a nursing home, that is ironically called Aurora House, where old people slide to the bottom of the social hierarchy, as they are deprived of their freedom and dignity, similarly to the fate of the fabricants. The way Sonmi refers back to Cavendish's time clearly indicates that it is their past - the early twenty-first century, which again leads us to the conclusion that Nea So Copros is the future of enhancing consumer capitalistic and materialistic domination of our present. The parallel between the two chapters is based on the perception of people who diverge from the values that a society demands from its members. Old people can be considered as the "human waste" (Mitchell 2014, 332) of society, due to the fact that they are not part of the workforce anymore, which makes them useless for the consumer capitalist state. Besides, they contradict consumer ideals, such as youth, fitness, and control over the body.

\section{The Natural Disaster of Consumerism}

The greatest contradiction — and the most telling motif — of the novel is the irony of the name Nea So Copros, since the word copros derives from the Greek kopros that apparently means excrement. This instance, consequently, bitterly illustrates consumer society in its entirety as waste. Furthermore, this notion reflects on the issue of waste production as well that is an inherent characteristic of consumerism, yet one which severely devastates the environment. The novel portrays the concerns critics of consumer culture maintain, namely, that by adopting a purely materialistic perspective, not only human relationships deteriorate, but humanity's relationship with its natural environment. On the one hand, this process can be considered as the result of the formerly mentioned alienation and estrangement. On the other hand, it may be observed as the consequence of the struggle to "consume" the environment in the sense of controlling and shaping it to our liking. It appears 
that humans have ceased to see the inherent value of nature and have begun to assume themselves superior to it. In this manner, by deluding themselves into believing that they have the right to dominate nature without any consequences, they feel empowered to take advantage of and make a profit out of it. However, this phenomenon articulates another range of ecological crises; Michael Carolan (2005) suggests that at this point we encounter a paradox, "in our attempt to control, we are simultaneously releasing onto the world entities that we cannot control . . . cross-species contamination from GM (genetically modified) foods, flood levees that break, and unmanageable forest fires, just to name a few such examples. Such is the irony of modern control: in seeking it we only make it more unattainable" (104).

Along these concerns, Cloud Atlas presents the dilemma revolving around the growth-based economy, which, noted by McLaughlin 1993 (cited in Smith 1998), is recognized as being "intrinsic to capitalism" (42), and the limitless expansion neoliberalists advocate. Sonmi's report of how "Nea So Copros is poisoning itself to death" (Mitchell 2014, 341), provides instances of what could be-and what already is - the result of present day natural exploitation: "Its soil is polluted, its rivers lifeless, its air toxloaded, its food supplies riddled with rogue genes. The downstrata can't buy the drugs necessary to counter these privations. Melanoma and malaria belts advance northwards at forty kilometers per year. Those Production Zones of Africa and Indonesia that supply Consumer Zones' demands are sixty per cent uninhabitable" (Mitchell 2014, 341).

Beside the devastation of soil, water and air, epidemics strike the populace, while more and more land becomes maximally depleted. Due to the immense power of the totalitarian regime, the public of Nea So Copros is thoroughly dazzled into ignorance of the environmental destruction falling on them, while those who are aware of it play the role of the "wilfully blind" (Mitchell 2014, 130). "The First Luisa Rey Mystery" portrays the advancing nuclear industry, and relevantly offers the remark about corruption that "every conscience has an off-switch hidden somewhere" (Mitchell 2014, 103). According to the plot, Luisa Rey, a journalist, aims to disclose the dangers of the new HYDRA reactor at Swannekke Island that gives place to Seabord Inc. - the provider of nuclear energy. Although the chapter remains faithful to its genre, the detective thriller, and in the end good conquers bad, we see that in the long-term, capital triumphs. Even though Luisa accomplishes her goal and averts a catastrophe in the 1970s, the reverberation of the same industry persists for more than a century reaching Nea So Copros in the form of a genomics unit that bears the name HYDRA as well, and that is responsible for manufacturing fabricants. This resemblance reinforces the message of the omnipotent authority of capital owners reaching across time and space, and the dangers of wilful ignorance. 
The degradation of the environment is, in fact, a current critical situation that requires attention and a solution. Besides the pollution of the environment, there is also the threat of overconsumption, that is, according to an explanation by Humphery 2010 (cited in McDonald and Wearing 2013), "the consumption of products and services 'at a level over and above that which is necessary to maintain a reasonable standard of living and at a rate that is greater than can be environmentally sustained in terms of resource provision and the handling of waste"' (115). This concept again resembles the figure of the cannibal and the notion of the uncivilized; how the satisfaction of immediate desires surpasses logic. The ignorance about environmental problems portrayed in the novel mirrors today's mainstream approach to the issue, which raises the question: how far can we go before we fall?

\section{Conclusion}

Given these points, it can be claimed that David Mitchell's Cloud Atlas depicts considerable issues concerning the social and environmental consequences of consumerism. The narrative structure, on the one hand, enables the reader to observe the capitalist economy and society from different times and perspectives; at its emergence, its culmination, and its collapse. On the other hand, by resembling a Russian doll, it mirrors the motif of incorporation that is central to the figure of the cannibal and its absurd motive for devouring. As a criticism on consumer culture, the novel questions the notion of civilization, and by juxtaposing the consumer society with tribes of cannibals, it challenges the concept of the consumer society. The chapter titled "An Orison of Sonmi-451" exemplifies the potential dangers of such a society, seeing that it displays humans that are created like commodities, treated utterly as instruments and slaughtered like animals. The way the privileged put millions of lives in jeopardy to secure their own social and financial power, or how the concept of human value drops out of sight to give place to monetary worth resembles current societal tensions. In addition, Cloud Atlas proposes the crisis of environmental destruction as an attribute of consumerist production, and foreshadows the danger of consuming our natural resources by the depiction of a post-apocalyptic community. In the light of the listed facts, I contend that Cloud Atlas incorporates the figure of the cannibal as the central motif to criticize consumer society for being not only short-sighted, but also for lacking a sense of humanity and civilization. 


\section{Works Cited}

Bartolovich, Chrystal. 1998. "Consumerism, or the Cultural Logic of Late Cannibalism." In Cannibalism and the Colonial World, edited by Francis Barker, Peter Hulme and Margaret Iversen, 204-237. Cambridge: Cambridge University Press.

Bayer, Gerd. 2015. "Perpetual Apocalypses: David Mitchell's Cloud Atlas and the Absence of Time." Critique: Studies in Contemporary Fiction 56 (4): 345-354. https://doi.org/10.1080/00111619.2014.959645

Bell, Daniel. 1978. "The Cultural Contradictions of Capitalism." In The Cultural Contradictions of Capitalism, edited by Daniel Bell, 33-84. New York: Basic Books.

Carolan, Michael S. 2005. "The Conspicuous Body: Capitalism, Consumerism, Class and Consumption." Worldviews: Global Religions, Culture, and Ecology 9 (1): 82-107. https://doi.org/10.1163/1568535053628436

Giroux, Henry A.. 2005. "The Terror of Neoliberalism: Rethinking the Significance of Cultural Politics.” College Literature 32 (1): 1-19. http://www.jstor.org/stable/25115243. Accessed 30 Mar. 2018. https://doi.org/10.1353/lit.2005.0006

Guest, Kristen. 2001. "Introduction: Cannibalism and the Boundaries of Identity." In Eating Their Words: Cannibalism and the Boundaries of Cultural Identity, edited by Kristen Guest, 1-10. Albany: State University of New York Press.

Hicks, Heather J. 2016. The Post-Apocalyptic Novel in the Twenty-First Century. Palgrave Macmillan US. https://doi.org/10.1057/9781137545848

Humphery, Kim. 2010. Excess: Anti-Consumerism in the West. Cambridge: Polity.

Johnston-Ellis, Sarah Jane. 2010. "David Mitchell's Cloud Atlas: 'Revolutionary or Gimmicky'? Massey Research Online. https://mro.massey.ac.nz/handle/10179/1685. Accessed 02 Apr. 2018.

Kasser, Tim. 2002. The High Price of Materialism. Cambridge: The MIT Press. https://doi.org/10.7551/mitpress/3501.001.0001 
McDonald, Matthew and Stephen Wearing. 2013. Social Psychology and Theories of Consumer Culture: A Political Economy Perspective. Hove: Routledge. https://doi.org/10.4324/9780203068038

McLaughlin, Andrew. 1993. Regarding Nature: Industrialism and Deep Ecology. Albany: State University of New York Press.

Mitchell, David. 2014. Cloud Atlas. London: Sceptre.

Mitchell, David. 2005. "Genesis." The Guardian, https://www.theguardian.com/ books/2005/apr/16/featuresreviews.guardianreview23. Accessed 02 Apr. 2018.

Mitchell, David. 2005. "Interview by Nazalee Raja." The Agony Column, http:// trashotron.com/agony/columns/2005/05-16-05.htm. Accessed 02 Apr. 2018.

Paterson, Mark. 2006. Consumption and Everyday Life. Abingdon: Routledge. https://doi.org/10.4324/9780203001769

Smith, Joseph Wayne and Gary Sauer-Thompson. 1998. "Civilization's Wake: Ecology, Economics and the Roots of Environmental Destruction and Neglect." Population and Environment 19 (6): 541-575. Springer, http://www.jstor.org/ stable/27503609. Accessed 06 Mar. 2018. 